\title{
Physiological and clinical effects of amylobarbitone sodium therapy in patients with anxiety states
}

\author{
LORNA WING AND M. H. LADER \\ From the Institute of Psychiatry, Maudsley Hospital, London, and the \\ Department of Pharmacology, University College, London
}

In a previous experiment (Lader and Wing, 1964), the palmar skin resistance was recorded in 20 patients with anxiety states and $\mathbf{2 0}$ normal controls. After a rest period, 20 identical auditory stimuli were applied automatically at intervals varying from 45 to 80 seconds to form a standard habituation procedure.

Three aspects of the skin resistance were studied. First, the background level, which is a measure of normal continuing sweat-gland activity, was analysed as its reciprocal, skin conductance. It was found that as the experiment proceeded the level of skin conductance tended to fall in the normal group, i.e., activity dropped, whereas it tended to rise in the group of patients. Secondly, the responses to the auditory stimuli were quantified and it was found that these responses (psychogalvanic reflexes) tended to diminish with repetition of the stimuli, i.e., they habituated. It was found that the normal group had large early responses which rapidly habituated whereas the patients had smaller early responses which persisted in size with little evidence of habituation. Thirdly, spontaneous skin conductance fluctuations were more frequent in the patients than in the normal group throughout the whole experiment.

These findings supported Malmo's theory (1957, 1959) that patients with anxiety states are chronically 'over-aroused'. However, we have elaborated the 'over-arousal' theory in that defective habituation was regarded as an important cause of the excess activity in the central nervous system. Thus, in the population at large, the rate of habituation is regarded as a property of the central nervous system which is distributed on a continuum and any individual's locus on that continuum is mainly genetically determined. In normal people, stressful situations cause a rise in the level of activity in the central nervous system which quickly falls again. In some individuals with defective habituation, stressful situations cause a rise in this activity which is greatly prolonged. This theory would predict that treatment of patients with anxiety states with sedative drugs would tend to return the physiological patterns in the direction of normal. It would also predict that such $\overrightarrow{\widehat{\phi}}$ treatment would cause improvement in some, at $\stackrel{\varrho}{a}$ least, of the clinical symptoms in parallel with the physiological changes.

Hamilton (1959) discussed the rating of clinical $\overrightarrow{-}$ progress in anxious patients. He pointed out that ${ }_{\sigma}^{\omega}$ change in the content of such patients' symptoms is rare, but the intensity with which they are experienced may be altered by treatment. He therefore recom- in mended scales designed to rate the severity of symptoms for use in clinical trials.

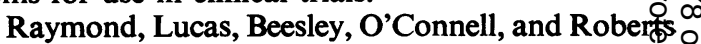
(1957) compared the effects of five drugs on anxio patients using a simple five-point scale to record $\vec{T}$ overall improvement or deterioration. Amyl 10 barbitone sodium $100 \mathrm{mg}$. t.d.s. was the only drig that was significantly better than the placebo. Thes workers did not examine individual symptoms: However, Hargreaves, Hamilton, and Roberis (1958) and Hamilton (1958), using benactyzine to $T$ treat patients with anxiety states, found that some symptoms improved on the drug while others did not. This suggests that the use of one overall rating of change may not be precise enough for the evaluation of drug effects.

The most widely used sedatives in the treatment of $\overrightarrow{\vec{A}}$ anxiety states are the barbiturates and the most $\frac{9}{3}$ usual barbiturate is amylobarbitone sodium. The purpose of the experiments to be described was to ascertain the effects of a week's treatment with amylobarbitone sodium compared with a placebo on the physiological measures and clinical symptoms:of patients with anxiety states. The experiment was 3 also in the nature of an assessment of the sensitivityo of the measures to barbiturate. It was hoped that $\frac{}{3}$ the physiological and clinical measures would prove sufficiently sensitive to enable formal comparative bioassays of sedatives to be attempted in later experi- $\frac{}{0}$ ments. Physiological recordings were made after a week's treatment with barbiturate and, again, after $N$ a second week's treatment with placebo. In addition, $N$ clinical changes were assessed by means of rating scales based on each patient's own symptoms. 
The same 20 patients with anxiety states studied in the experiments reported previously (Lader and Wing, 1964) were used again, and the diagnostic criteria applied are set out in full in that report. Of the 10 males, eight patients had 'free-floating' anxiety, one had anxiety together with some symptoms of mild depression, and one had 'situational' anxiety, i.e., anxiety confined to certain specific situations. Seven of the 10 female patients suffered from 'free-floating' anxiety, one had mild depressive features in addition to anxiety, and two had 'situational' anxiety states. The ages of the patients ranged from 19 to 53 . The duration of illness ranged from four weeks to 19 years but it was less than one year in 10 of the 20 patients.

Most of the patients had received sedatives or tranquillizers in the past, but all drugs were stopped for at least 48 hours before the trial began, and for one week in the case of long-acting drugs such as the phenothiazines.

\section{DRUGS}

The active drug was amylobarbitone sodium made up into tablets each containing $65 \mathrm{mg}$. (1 grain). The dosage for every patient was one tablet three times a day, i.e., a total daily dose of about $200 \mathrm{mg}$. No allowance was made for sex, weight, or body surface area. The placebo was lactose made up into similar tablets. One tablet was taken three times a day.

\section{EXPERIMENTAL DESIGN}

Half the patients, five males and five females, received amylobarbitone sodium $65 \mathrm{mg}$. t.d.s. for one week. At the end of the week the patients were re-assessed clinically and the physiological recording with the habituation procedure was carried out. For the second week, they received placebo t.d.s. and at the end of it they were re-assessed and the physiological recordings were repeated. The other half of the patients received the drugs in the reverse order. The patients were allotted to the treatment orders in a random fashion subject to five patients of each sex being allotted to each treatment order.

The entire experiment was carried out double blind, i.e., neither the patient nor the experimenters knew the identity of any week's treatment. The trial, therefore, was of a balanced cross-over design with double blind procedure.

INFORMATION GIVEN TO THE PATIENTS The patients were told that the tablets had been in clinical use for a long time and had proved helpful for some people who were tense and anxious. The general attitude was that the tablets might alleviate the patient's symptoms, but that this could not be guaranteed. The patients' active cooperation in the experiment was invited and they responded with interest and enthusiasm. They were not told until after the trial that half of the tablets were inert but no one then objected to the procedure.
MEASUREMENT OF SKIN RESISTANCE The technique for the measurement of skin resistance was the same as that reported in detail elsewhere (Lader, 1964).

Double-element lead electrodes were used to prevent polarization artefacts. The inactive electrode was strapped over an abraded area above the right elbow. The active electrode site was the palmar surface of the distal phalanx of the right thumb. A masking device in the form of an annular foam plastic corn plaster of internal diameter $9.5 \mathrm{~mm}$. was applied, and at both electrode sites an electrode jelly containing 0.05 M sodium chloride was used. A constant current of 10 microampères was passed through the electrodes and the voltage produced was balanced back in steps of $0.25 \mathrm{v}$ (equivalent to 25 kilohms). The sensitivities available were equivalent to full-scale deflection of \pm 100 kilohms, \pm 50 kilohms, and \pm 25 kilohms. The residual voltage was fed into a Grass amplifier which drove an ink-writing pen-oscillograph.

STIMULATION PROCEDURE Each stimulus was a 1,000 c.p.s. pure tone of one second's duration, standardized as 1 volt across a 3-ohm loudspeaker. The intensity was measured with a Dawes sound-level meter and it was found to be $100 \mathrm{db}$ above a reference source of 0.0002 dynes/sq. cm. Twenty of these stimuli were presented automatically in a pre-determined sequence at intervals varying randomly from 45 to 80 seconds.

\section{CLINICAL MEASUREMENTS}

RATINGS OF OVERT ANXIETY Before the physiological recording started, one of us (L.W.) rated the patient for overt anxiety on a seven-point scale ranging from 0 , no overt anxiety, to 6 , very severe anxiety. The ratings were made on the overall behaviour of the patient during the application of the electrodes.

DAILY RATING OF SYMPTOMS The method used was a modification of scales described by Rosner, Levine, Hess, and Kaye (1955) and Black (1959). One of the forms used is shown in Figure 1.

At the first interview, the symptoms of the patient described in his own words were entered in the spaces on the left hand side of the form: for example, "thumping of the heart', 'a feeling of anxiety which never goes away', 'afraid to go on the underground', 'tiredness and loss of interest'.

When the list was completed, the patient was asked to make a mark on the horizontal lines (all $10 \mathrm{~cm}$. in length) to show how severe each of his symptoms had been for the few days before the beginning of the experiment during which no drug had been given. The words under the lines were intended as guides but any part of the line could be used to indicate the degree of severity. This first rating was used as the 'baseline', that is, the clinical state immediately before the commencement of the trial.

The patient was then given a week's supply of forms, each dated and typed with his symptom list. He was asked 
NAME TO BE FILLED IN ON........

On the day stated above, please complete this form in the evening before going to bed. Having completed it, please place it in the envelope provided for the completed forms. Do not look at the other forms before completing this one. Do not compare notes with anyone else.

Underneath, you will find a list of symptoms with a line beside each. At one end of the line is written 'Very Severe'; in the middle'Moderate', and at the other end-'Absent'. Show how much each symptom has troubled you during the day which has just passed by putting a mark in the appropriate place on the corresponding line, e.g. if the symptom has been very severe, put a mark at the right-hand end: if it has troubled you only a little, put a mark somewhere towards the left, and so on. Do this for each symptom in the list and then put the form away in the envelope.

SYMPTOMS
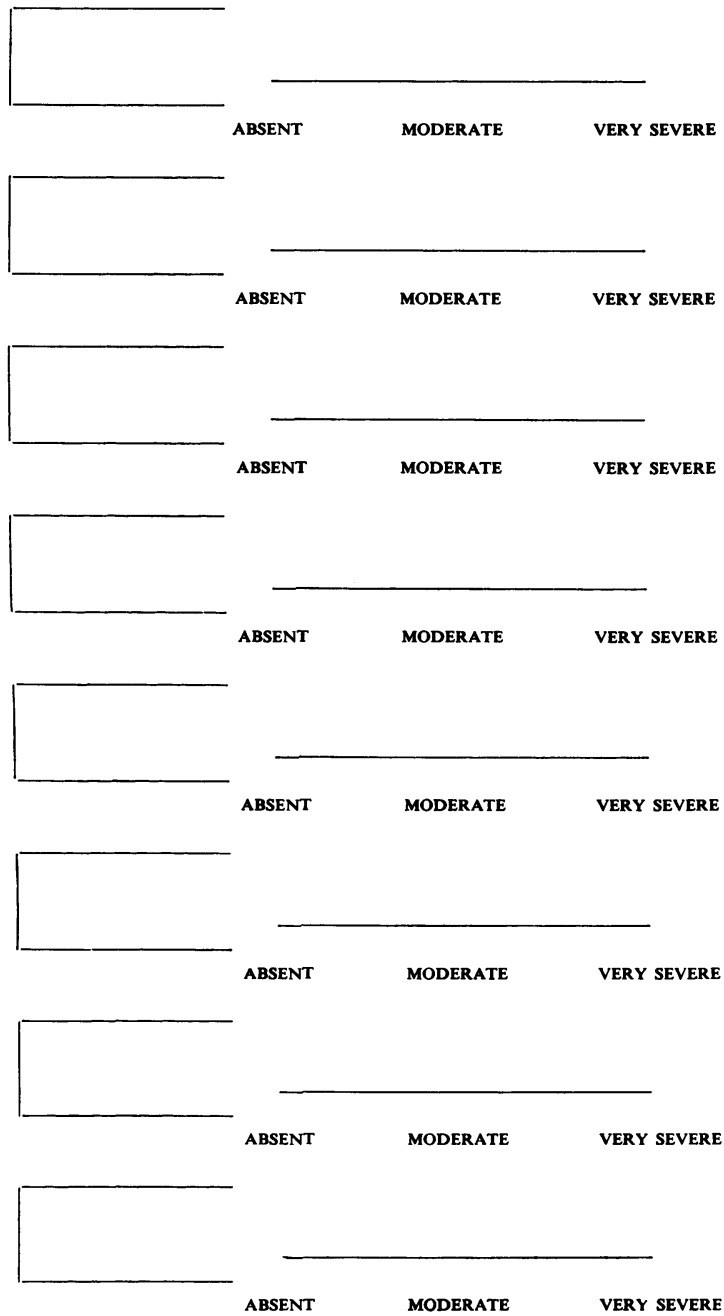

PLEASE BRING ALL THESE FORMS WITH YOU THE NEXT TIME YOU ATTEND HOSPITAL

FIG. 1. Form used for the daily ratings of symptoms. to complete one each evening without referring to his previous ratings.

WEEKLY RATING OF SYMPTOMS At the end of each week, after completion of the physiological tests, the patients were asked if there had been any change in their symptoms. A nine-point scale was used to rate each symptom with 0 as no change, -4 as much worse, and +4 as much better. For both weeks, the comparison was made between the present state and the state before the trial started. Patients were not asked to compare the second week with the first.

SIDE EFFECTS Each patient was asked for details of side effects when the weekly rating was completed.

\section{EXPERIMENTAL CONDITIONS AND PROCEDURE}

The patients sat in a comfortable armchair in a sound- $\vec{O}$ protected room, the temperature of which was controlled at $22-24^{\circ} \mathrm{C}$. The recording equipment was in an adjacent $\vec{\omega}$ room from which the patients could be observed through a one-way screen. The patients were aware that they were under observation throughout the experiment.

Each patient reported to the laboratory at the end of $\infty$ each week's treatment bringing with him the completed forms for that week. He was brought into the experimenta room and the electrodes were affixed. During this tim the patient was rated for overt anxiety. The patient waß told that the procedure would be the same as that of the pre-drug test: a rest period followed by a series of sounds $T$ to which he was to make no active response.

The room lights were dimmed, the patient was le $\hat{p}$ alone and recording started. After 11 minutes, 20 audito stimuli were applied and recording terminated one minue after the last stimulus. The electrodes were then removed of and the patient was questioned regarding the effects of $\mathrm{V}$ the previous week's treatment on his symptoms.

\section{ANALYSIS OF SKIN RESISTANCE RECORDINGS}

SKIN CONDUCTANCE LEVELS The skin resistance level 음 was read at one-minute intervals before the stimuli $\stackrel{\mathbb{Q}}{2}$ started, just before each of the 20 stimuli and once at the $\overrightarrow{\bar{\sigma}}$ end of the experiment. For reasons outlined elsewhere $\frac{0}{3}$ (Lader, 1964), the resistance values (in kilohms) were con- $\vec{J}$ verted to $\log$ conductance values (in $\log$ micromhos). The $32 \mathrm{log}$ conductance values were averaged in groups of four to give eight values, three during the rest period and five during the stimuli.

PSYCHO-GALVANIC REFLEXES The skin resistance at the

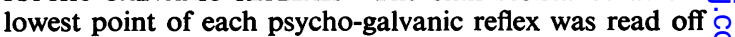
and converted to $\log$ conductance. From this value was subtracted the log conductance value at the beginning of the response to give the psycho-galvanic reflex mea- $\triangle$ sured in terms of change in log conductance.

SPONTANEOUS SKIN CONDUCTANCE FLUCTUATIONS The skin resistance fluctuations were counted for 40 -second $\sigma$ periods out of the minute intervals before the stimuli $N$ started, for 40-second periods before each of the stimuli, and for the final $\mathbf{4 0}$ second period. 
The criterion used was a log conductance change of $0.003 \log \mu$ mhos and the technique for applying such a criterion to a resistance trace has been explained previously (Lader, 1964).

The 32 counts were added into eight groups of four, three during the rest period and five during the stimuli.

\section{ANALYSIS OF RATING SCALES}

DAILY RATINGS For each symptom, the distance from the left hand end of the line to the mark made by the patient was measured to the nearest centimetre.

Since each patient provided his own description of his symptoms, direct comparisons could not be made from the raw data. However, it was found that all the symptoms could be grouped into four categories. 1 Physical symptoms, i.e., autonomic or muscular, such as palpitations or shakiness; 2 general anxiety (usually expressed as a 'feeling of fear'; 3 situational anxiety, e.g., dislike of travelling on public transport because of exacerbation of symptoms; 4 depressive symptoms. These were believed by the patients to be a consequence of their anxiety, and except in two cases, were given little prominence in the description of symptoms.

The distribution of the daily ratings was examined. It was found that, for each patient, ratings of symptoms classified under the same heading were sufficiently close to allow the scores to be combined. The mean was calculated to the nearest centimetre. If a symptom category was not represented a score of 0 was given.

A mean daily score for each symptom category was calculated from the ratings made on the last three days of each week. This was to allow for build-up of drug effects and for any possible carry over from the previous week which might have affected the first few days. The mean scores for each symptom category were subtracted from the baseline scores obtained at first interview, and this value was used in the final statistical analysis.

WEEKLY RATING Scores were given on the nine-point scale as described previously and symptoms were combined into categories as above. The mean was taken to the nearest whole number. These scores were obtained as comparisons with the baseline, so no further correction was needed.

\section{STATISTICAL ANALYSIS}

The distributions of the data obtained from the physiological measures and from the clinical rating scales were sufficiently close to normality to allow parametric statistics to be used. A split-plot type of analysis of variance was used (Cochran and Cox, 1957). Both the drug effects and occasion effects were tested against the within-patient residual error variance. As none of the occasion effects was significant, only drug effects will be presented.

\section{RESULTS}

PHYSIOLOGICAL MEASUREMENTS In Fig. 2 are shown examples of skin resistance records from a patient

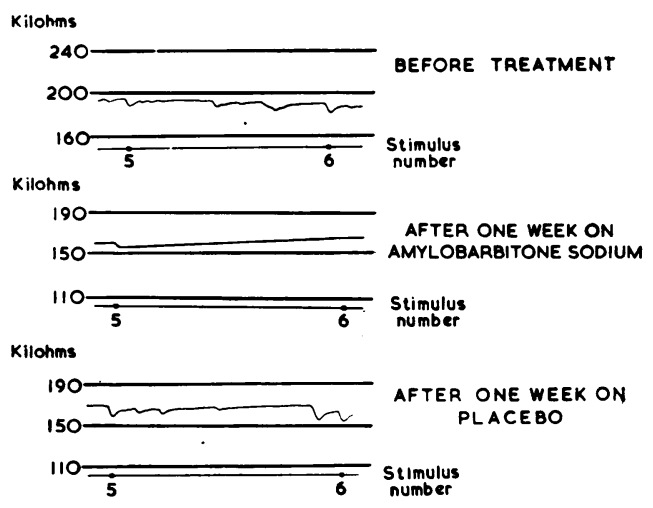

FIG. 2. Examples of skin resistance traces from a patient with anxiety state before treatment, after a week's treatment with amylobarbitone sodium, and after a week's treatment with placebo.

before drug treatment, on amylobarbitone sodium, and on placebo. Before treatment, the skin resistance is tending to fall, i.e., conductance rises, and there are definite responses (psycho-galvanic reflexes) to stimuli numbers 5 and 6 . Many spontaneous fluctuations can be seen. After one week on amylobarbitone sodium, $65 \mathrm{mg}$. t.d.s., the resistance level is lower but is tending to rise and whereas there is a small response to stimulus number 5 , there is none to the next stimulus. Furthermore, no spontaneous activity is discernible. After the week on placebo, the skin resistance shows little tendency to rise, responses to both stimuli and much spontaneous activity are apparent: the trace is very similar to the pre-treatment one.

Skin conductance levels (sweat-gland activity) The graphs depicting treatment effects on the mean

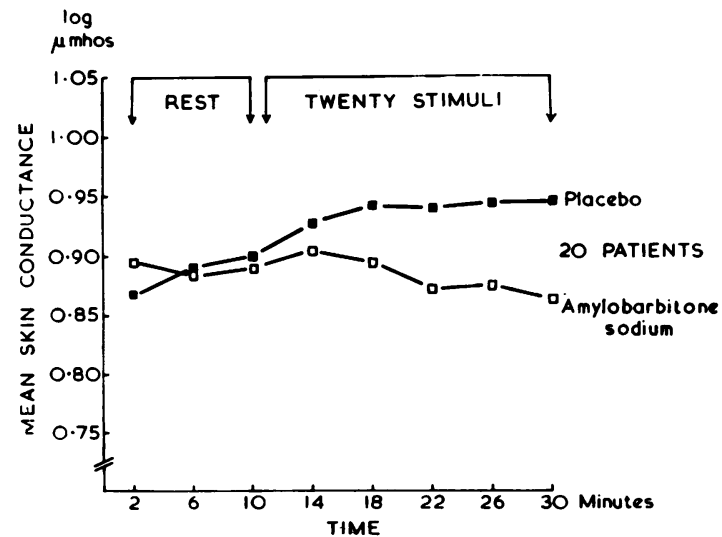

FIG. 3. The effects of 20 auditory stimuli on the skin conductance. Each point represents the mean of four log conductance readings. 
skin conductance levels of the patients are shown in Figure 3. The mean skin conductance for the patients on placebo rises steadily throughout the experiment. With amylobarbitone sodium, the conductance level is fairly constant during the first half of the experiment and then it decreases. The conductance levels for the two treatments do not differ significantly at any time during the experiment. Conductance levels, per se, have a high variance. Neither the change in conductance during the rest period (time 2 minus time 10 ) nor the change during the stimulation procedure (time 14 minus time 30 ) is significantly different for the two treatments. The only skin conductance variable to show significant treatment effects is the change in conductance from beginning to end of the experiment (time 2 minus time 30 ) referred to subsequently as 'total conductance change'. An $F$ ratio of 12.80 (1,16 d.f.), significant beyond the 0.01 level of probability, was obtained. The mean placebo change was negative; the mean barbiturate change was positive. Of the 20 patients, in 16 the change with barbiturate was more positive than with placebo; in four, the drug change was more negative, i.e., an effect opposite to the mean effect was obtained.

Psycho-galvanic reflexes (sweat-gland responses) Previous work had shown that habituation of the psycho-galvanic reflexes tended to follow an exponential course (Lader, 1964). Therefore, the mean psycho-galvanic reflexes (ordinate $\mathrm{Y}$ ) were plotted against the logarithm of the stimulus number (abscissa X) as shown in Figure 4. The first responses are distinct and they were analysed separately. The mean responses to stimuli nos. 2 to 20 inclusive are rather scattered but they lie around straight lines for both drug and placebo. The regression lines of mean responses on log stimulus numbers were calculated in the usual way (Snedecor, 1956):

For placebo, $\mathrm{Y}=0.046-0.020 \mathrm{X}$

For barbiturate, $Y=0.047-0.026 \mathrm{X}$

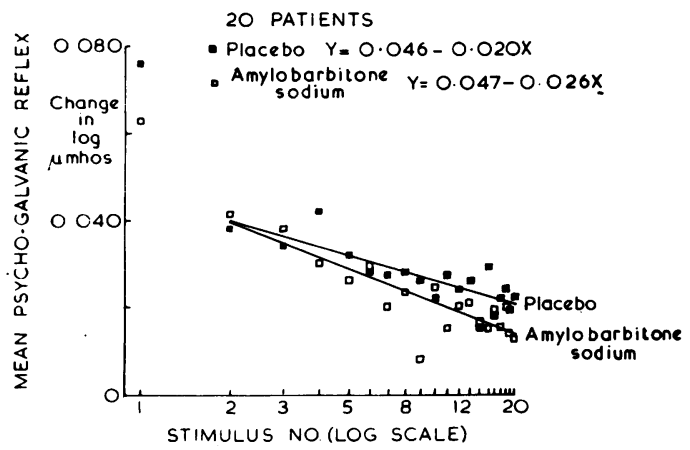

FIG. 4. Habituation regression lines of the psychogalvanic reflex.
The constants 0.046 and 0.047 are the 'a values', the $Y$ intercepts, i.e., the points on the $Y$ axis which would be intersected by the regression lines if they were extrapolated to the left. The constants -0.020 and -0.026 are ' $b$ values', the regression coefficients or slopes of the lines. The more negative the $b$ value, the steeper the slope and the more rapid is the rate of habituation. The more negative value for the barbiturate shows that the drug caused a more rapid rate of habituation than the placebo.

For each of the 20 patients, two regression equations each with an a value and $a b$ value were calculated, one for the placebo responses and one for the amylobarbitone sodium responses. A complication arose in that some of the patients habituated to zero response especially on the barbiturate occasion. An arbitrary criterion was adopted for assessing when complete habituation had occurred. When three consecutive stimuli failed to elicit any discernible responses, total habituation was judged to have occurred. Therefore, when calculating the regression line for the responses, the third zero response was regarded as the last one of the series of responses and any later responses due to dishabituation were disregarded.

The a values and $b$ values were significantly cor related, those subjects with large early responses tending to have steeper slopes of habituation. There fore, the $b$ values were corrected for their dependence on the corresponding a values by routine regressiom techniques (Snedecor, 1956). Two scores termed. 'habituation scores' (H scores) were obtained for each $\vec{\varphi}$ patient, one for the placebo habituation sequence and of one for the barbiturate. The $\mathrm{H}$ score, then, is the slope of habituation corrected for the $Y$ intercept.

The statistical results are given in Table I. There is no significant difference between the treatments for either the size of the first responses or the a $\mathbb{D}$ values. The rate of habituation (b value) is significantly increased by the barbiturate as compared with placebo $(\mathrm{P}<0.05)$. The corrected rates of habituation, the $\mathrm{H}$ scores, are greater for the drug than the placebo at a slightly higher level of significance $(P<0.02)$.

The $\mathbf{H}$ scores did not yield a high discrimination between the treatments. Of the 20 patients, in 15

TABLE I

\begin{tabular}{lcc} 
Variable & \multicolumn{2}{c}{ Amylobarbitone Sodium v. Placebo } \\
\cline { 2 - 3 } & $\begin{array}{l}\text { F Ratio } \\
(\mathrm{df}: 1,16)\end{array}$ & Significance \\
\hline 1st P.G.R. & $<1$ & $\mathrm{Nil}$ \\
a value & $<1$ & $\mathrm{Nil}$ \\
b value & 6.05 & $<0.05$ \\
H score & 7.55 & $<0.02$
\end{tabular}


the rate of habituation was more rapid for the barbiturate than for the placebo; in five the placebo rate was the more rapid.

Habituators and non-habituators When the regression slopes (b values) were being calculated, the statistical significance of each regression slope could be tested (Snedecor, 1956). If the slope was found to be significantly negative at the 0.05 level of confidence or beyond, habituation was regarded as having occurred. Conversely, if the slope was not significantly negative, habituation was deemed not to have occurred. Therefore, each of the 40 regression slopes could be categorized as 'habituated' or 'non-habituated'. Six patients habituated on both occasions and six on neither occasion. The remaining eight patients habituated on the amylobarbitone sodium occasion but not on the placebo occasion. These values can be placed in a 'cross-over chi-square' table (McNemar, 1955):

\begin{tabular}{llcc} 
& & \multicolumn{2}{c}{ Placebo Occasion } \\
\cline { 3 - 4 } & & Habituated & Did not Habituate \\
\cline { 3 - 4 } $\begin{array}{l}\text { Amylobarbitone } \\
\text { Occasion }\end{array}$ & Habituated & 6 & 8 \\
$\begin{array}{l}\text { Did not } \\
\text { habituate }\end{array}$ & 0 & 6
\end{tabular}

The chi-square value is $\frac{(8-0-1)^{2}}{8+0}=6 \cdot 13$. With 1 degree of freedom, $\mathrm{P}<0.025$. It may be concluded that the barbiturate changed some non-habituators to habituators.

Spontaneous skin conductance fluctuations (sweatgland fluctuations) The effects of the two treatments on the mean number of spontaneous fluctuations are shown in Figure 5. The two lines are roughly parallel with the mean number being lower for the amylobarbitone sodium. The lines drop during the first part of the rest period and then they tend to rise slightly at the end of the rest period. This may have

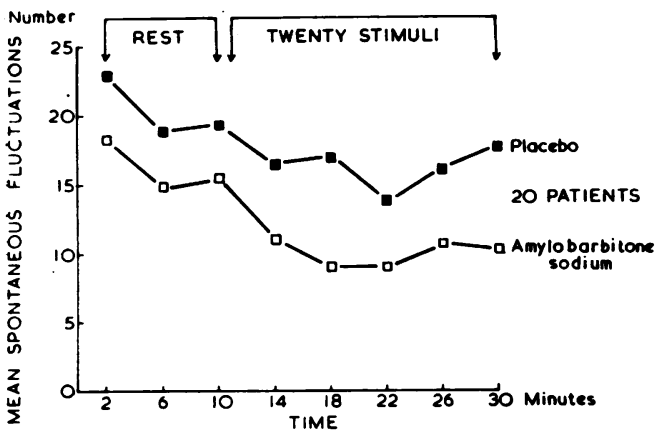

FIG. 5. The effects of 20 auditory stimuli on the number of spontaneous skin conductance fluctuations. Each point represents the number of fluctuations counted for four periods of 40 seconds. been an anticipation effect. During the first part of the stimulation procedure the fluctuations tend to drop only to rise somewhat at the end of the experiment.

There is a significant difference between the two treatments at the start of the experiment but this significance is lost in the remainder of the rest period (see Table II). The significance is regained at the next point (time 14) and it persists throughout the rest of the experiment. The numbers of fluctuations at times 26 and 30 were added together to give a variable which will subsequently be referred to as 'fluctuations at end of experiment'. An $F$ ratio of 12.27 (1,16 d.f.; $P<0.01)$ was obtained for this variable.

\section{TABLE II}

SPONTANEOUS SKIN CONDUCTANCE FLUCTUATIONS DATA

\begin{tabular}{lcc} 
Variable & \multicolumn{2}{c}{ Amylobarbitone Sodium v. Placebo } \\
\cline { 2 - 3 } & $\begin{array}{l}\text { F Ratio } \\
\text { (df: 1,16) }\end{array}$ & Significance \\
\hline Number at time 2 & 6.93 & $<0.025$ \\
Number at time 6 & $<4$ & None \\
Number at time 10 & 4.10 & None \\
Number at time 14 & 14.76 & $<0.01$ \\
Number at time 18 & 22.81 & $<0.001$ \\
Number at time 22 & 7.04 & $<0.025$ \\
Number at time 26 & 12.31 & $<0.01$ \\
Number at time 30 & $9 \cdot 12$ & $<0.01$ \\
Number at time 26 plus & 12.27 & $<0.01$ \\
time 30 & &
\end{tabular}

For 18 out of the 20 patients, the number of fluctuations at end of experiment were lower with the amylobarbitone sodium than with placebo. In only two was the number lower with placebo.

Discriminant-function analysis and overt anxiety ratings Three variables appeared to be fairly sensitive to drug effects. They were total conductance change, $\mathrm{H}$ score, and fluctuations at end of experiment. These variables were also those which had discriminated best between the patients with anxiety states and the normal subjects in the previous predrug experiment (Lader and Wing, 1964). In that experiment the three variables had been combined in such a way as to yield the maximum discrimination between the groups using the statistical technique known as discriminant-function analysis (Fisher, 1954). The equation which was derived was:

Discriminant-function score (pre-drug) $=-0.074$ (total conductance change) +0.485 (H score) + 0.001278 (fluctuations at end)

The higher the $\mathrm{D}$ score, the greater was the composite physiological activity. In the present experiment, the data for each patient were inserted into the above equation. Thus, two scores were obtained for each patient, one for the placebo occasion (D placebo) and one for the amylobarbitone sodium 
occasion (D amylobarb.). Also, a D score had been obtained before the treatment started (D pre-drug) (Lader and Wing, 1964). Lastly, the difference between the $\mathrm{D}$ placebo and $\mathrm{D}$ amylobarb. (D change) gave some estimate of the effect of the barbiturate on the composite physiological activity.

An analysis of variance for the $D$ placebo and $D$ amylobarb. scores was carried out. An F ratio of 21.39 $(\mathrm{P}<0.001)$ was obtained for the difference between the treatments.

The $D$ change score was positive in 19 out of the 20 patients, indicating that not only did the $D$ predrug equation yield scores able to discriminate between normal controls and anxious patients but also scores able to discriminate between the patients when on placebo and when on amylobarbitone sodium.

The product-moment correlation between the $D$ pre-drug scores and the $D$ placebo scores was $+0.60(P<0.01)$. This correlation would have been much greater $(r=+0.76 ; P<0.001)$ but for one patient. This was a patient with situational anxiety restricted to new situations. On the first time of testing, she was anxious and gave a high $\mathrm{D}$ pre-drug score. On the placebo occasion, the situation had lost its novelty, she was no longer anxious, and a low D placebo score was obtained.

\section{CLINICAL MEASUREMENTS}

RATINGS OF OVERT ANXIETY Ratings of overt anxiety were made on both the drug occasions. The rating was higher on the placebo occasion than the barbiturate occasion in 15 patients; it was equal in four patients and lower in one patient: thus, there was significantly less overt anxiety on the barbiturate occasion than the placebo $(P<0.01$; sign test; Siegel, 1956).

The rank correlation coefficient between the overt anxiety ratings on the placebo occasion and the D placebo scores was $+\mathbf{0 \cdot 2 8}$ (not significant). The rank correlation between the amylobarbitone sodium anxiety ratings and the $\mathrm{D}$ amylobarbitone scores was $+0.60(P<0.002)$. The correlation between the changes in overt anxiety ratings and the $D$ change scores was $+0.42(P=0.05)$. It may be concluded that the overt anxiety ratings on the barbiturate occasion but not on the placebo occasion are related to the equivalent measure of composite physiological activity; furthermore, there is a just significant relationship between improvement in overt anxiety with treatment and change in composite physiological activity.

CORRELATIONS BETWEEN DAILY AND WEEKLY SYMPTOM RATINGS The differences between ratings on
TABLE III

CORRELATIONS BETWEEN DAILY AND WEEKLY RATINGS OF SYMPTOMS

\begin{tabular}{lcc} 
Symptom Category & $\boldsymbol{r}$ & Significance \\
\hline Physical symptoms & $\mathbf{0 . 7 4}$ & $<0.01$ \\
General anxiety & $\mathbf{0 . 4 1}$ & None \\
Situational anxiety & $\mathbf{0 . 3 3}$ & None \\
Depression & -0.09 & None
\end{tabular}

the drug and placebo were obtained for each patient, and product-moment correlations were calculated between the daily and the weekly scores for each symptom category. The results are shown in Table III. The highest correlation was between the two ratings of physical symptoms and this was the only one to reach an acceptable level of significance.

COMPARISON BETWEEN EFFECT OF DRUG AND OF PLACEBO Physical symptoms were rated as less severe during treatment with the drug than with the placebo. This was significant for both the daily and the weekly scores (see Table IV).

TABLE IV

EFFECTS OF TREATMENT WITH DRUG COMPARED WITH:

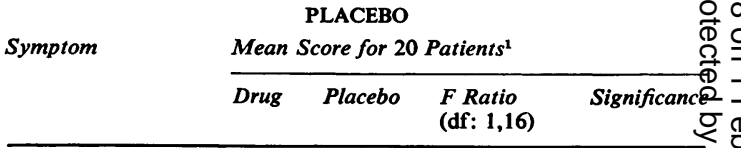

\begin{tabular}{|c|c|c|c|c|}
\hline $\begin{array}{l}\text { Daily score } \\
\text { Physical } \\
\text { General anxiety } \\
\text { Situational anxiety } \\
\text { Depression }\end{array}$ & $\begin{array}{l}2 \cdot 7 \\
1 \cdot 7 \\
2 \cdot 0 \\
1 \cdot 1\end{array}$ & $\begin{array}{l}1.6 \\
1.8 \\
2.0 \\
0.5\end{array}$ & $\begin{array}{l}6 \cdot 39 \\
<1 \\
0 \\
2 \cdot 24\end{array}$ & $\begin{array}{l}<0.05 \\
\text { None } \\
\text { None } \\
\text { None }\end{array}$ \\
\hline $\begin{array}{l}\text { Weekly score } \\
\text { Physical } \\
\text { General anxiety } \\
\text { Situational anxiety } \\
\text { Depression }\end{array}$ & $\begin{array}{l}1.9 \\
0.6 \\
0.3 \\
1.0\end{array}$ & $\begin{array}{l}0.4 \\
0 \\
-0.2 \\
-0.3\end{array}$ & $\begin{array}{l}6 \cdot 72 \\
1 \cdot 64 \\
1 \cdot 16 \\
6 \cdot 83\end{array}$ & $\begin{array}{l}<0.05 \\
\text { None } \\
\text { None } \\
<0.05\end{array}$ \\
\hline
\end{tabular}

${ }^{1} \mathrm{~A}$ positive score indicates improvement and a negative score deterioration, from baseline level.

General symptoms of anxiety showed virtually no difference on the daily scores, and a slight advantage for the drug on the weekly score which was not significant.

Situational anxiety symptoms were also only slightly affected by the drug. For depressive symptoms, a slight insignificant advantage for the drug, as compared with the placebo, was found on the mean daily score; on the weekly rating the drug superiority was significant.

The scores for different symptoms cannot be compared. This is because all patients had physical symptoms, but did not necessarily have each of the other three possible symptom categories.

COMPARISON WITH BASELINE If all the patients had recorded 'no change' on either tablet, the total for 
TABLE V

SIGNIFICANCES OF THE CHANGES FROM BASELINE PRODUCED BY THE DRUG AND THE PLACEBO

\begin{tabular}{|c|c|c|c|c|}
\hline Symptom & $\begin{array}{l}\text { Drug } \\
\text { t(df: } 16\end{array}$ & Significance & $\begin{array}{l}\text { Placebo } \\
\text { t(df: 16) }\end{array}$ & Significance \\
\hline $\begin{array}{l}\text { Daily rating } \\
\text { Physical Symptoms } \\
\text { General anxiety } \\
\text { Situational anxiety } \\
\text { Depressive symptoms }\end{array}$ & $\begin{array}{l}5 \cdot 87 \\
2 \cdot 62 \\
5 \cdot 01 \\
2 \cdot 75\end{array}$ & $\begin{array}{l}<0.001 \\
<0.05 \\
<0.001 \\
<0.05\end{array}$ & $\begin{array}{l}3 \cdot 37 \\
2 \cdot 77 \\
5 \cdot 01 \\
1 \cdot 25\end{array}$ & $\begin{array}{l}<0.01 \\
<0.05 \\
<0.001 \\
\text { None }\end{array}$ \\
\hline $\begin{array}{l}\text { Weekly rating } \\
\text { Physical symptoms } \\
\text { General anxiety } \\
\text { Situational anxiety } \\
\text { Depressive symptoms }\end{array}$ & $\begin{array}{l}3 \cdot 18 \\
1 \cdot 26 \\
<1 \\
2 \cdot 08\end{array}$ & $\begin{array}{l}<0.01 \\
\text { None } \\
\text { None } \\
\text { None }\end{array}$ & $\begin{array}{l}<1 \\
0 \\
<1\end{array}$ & $\begin{array}{l}\text { None } \\
\text { None } \\
\text { None } \\
\text { None }\end{array}$ \\
\hline
\end{tabular}

the daily and weekly ratings would have been 0 . Table $V$ shows the significances of the changes from this baseline. These were calculated by means of $t$ tests, using the error variances obtained from the appropriate analysis of variance.

It can be seen that daily ratings showed significant improvement from baseline for all symptoms, both for drug and placebo, with the exception of depression while on the placebo.

With the weekly ratings only the drug effects on physical symptoms were significantly different from the baseline. Situational anxiety and depression showed a slight insignificant deterioration on the placebo.

SIDE EFFECTS Six patients reported side effects while on the drug. Of these, four complained of daytime drowsiness, one of a 'thick-headed' feeling, and one described 'weakness' occurring soon after taking the first few doses. Two of the six patients had the same side effects on the placebo (drowsiness and 'thick-headedness' respectively). One other patient complained of feeling 'thick-headed' on the placebo only. The side effects were of little consequence except in the case of one woman who was extremely sleepy.

\section{DISCUSSION}

The experimental design used was the balanced cross-over design in which each patient receives both treatments in succession, that is, he acts as his own control. The design is widely used in the evaluation of drugs in psychiatric patients. The alternative, that of using two groups of patients each given one drug, is generally unsatisfactory as it is necessary to match the groups in as many ways as possible. Lewis (1958) states: "matching psychiatric groups for this purpose is a daunting business, since they should be at least alike in the distribution of sex, age, intelligence, duration of illness, form and severity of illness, and previous illness'. The use of patients as their own control circumvents the problem of matching of patients.
The effect of the amylobarbitone sodium on the skin conductance level as compared to placebo was to change a rising trend during the experiment to a falling trend. Assuming that the skin conductance level is dependent on some aspect of activity of the central nervous system, it may be inferred that with placebo, this activity rises whereas with the barbiturate, the activity drops, i.e., adaptation occurs. This alteration with the sedative drug is in the direction of the trend found in normal control subjects (Lader and Wing, 1964), although the degree of alteration is relatively small and the mean normal pattern is not nearly attained.

The actual levels were not significantly affected by the barbiturate. The skin conductance level, per se, tends to have a high variance so that small drug effects would not be significant. Of the changes in level throughout various parts of the experiment, only that between the beginning and end of the experiment was significant. This variable covers the maximum time interval of 28 minutes so that trends are most easily detected.

The number of spontaneous fluctuations was lessened by the barbiturate, i.e., the change was in the direction of those levels obtaining in normal control subjects (Lader and Wing, 1964). A similar 'normalizing' effect of amylobarbitone sodium on respiratory patterns was described by Coppen and Mezey (1960). They found that anxious patients have inefficient respiration as compared with normals and that the respiratory inefficiency tends to be minimized by the administration of one dose of $200 \mathrm{mg}$. of amylobarbitone sodium.

Reactivity, as assessed by the size of the first psychogalvanic reflex and the a value, was not affected by the barbiturate. Habituation was accelerated significantly but the mean effect was small. This increase in the rate of habituation is to be expected from the results obtained in normal subjects (Lader, 1964). In these experiments, it was found that cyclobarbitone accelerated habituation and the acceleration bore a rectilinear relationship to the dose of drug.

Of the variables, the habituation score was the least consistently affected by the drug, five out of 20 patients habituating more rapidly with the placebo. It might be argued that this inconsistency was due to the complex mathematical derivation of the variable obscuring the drug effect. However, in the previous experiment (Lader and Wing, 1964), the H score discriminated best between anxious patients and normal subjects. It is concluded that the $\mathrm{H}$ score in patients with anxiety states is fairly resistant to sedative drug effects.

The $\mathbf{D}$ pre-drug scores and the $\mathbf{D}$ placebo scores, representing 'composite physiological activity' at the 
pre-drug testing and after a week on placebo, correlated significantly. This correlation reached +0.76 if one patient was excluded on the grounds that the discrepancy in her case was explicable in terms of her situational anxiety regarding new experiences. This suggests that the $D$ scores empirically reflect a function of the central nervous system in patients with anxiety states which is fairly constant over a short term.

The overt anxiety ratings correlated significantly with the $\mathrm{D}$ scores on the amylobarbitone sodium occasion but not the placebo occasion. No simple explanation is apparent but it is possible that it is difficult to assess the overt anxiety of patients not reacting to a novel situation as on the preliminary occasion (when the correlation was very high) and yet who are not sedated.

The change in overt anxiety with the drug correlated with the change in $D$ score at a level of significance just at the 0.05 level. Again, it is possible that the difficulty in the assessment of overt anxiety on the placebo occasion caused some inaccuracy. However, it does appear that there is a weak relationship between change in clinical anxiety and change in physiological activity.

With the rather low dose of amylobarbitone sodium used, clear-cut superiority of drug over placebo was shown in the physical symptoms alone. The difference was significant only at the 0.05 level of probability but appeared in both the daily and the weekly ratings. This might mean that the physical symptoms were the most accurately assessable and hence the most likely to show up any general improvement with drug therapy. A second explanation would be that sedative drugs have a differential effect and that physical symptoms are the most amenable to treatment. In view of the correlation between the daily and weekly ratings for the physical symptoms being the only one to reach significance, the former is the more likely explanation. An editorial (Editorial, Brit. med. J., 1962) suggested that the barbiturates have maintained a reputation for the treatment of anxiety states because "no one suggests that they provide more than partial symptomatic relief'. The present experiment confirms this view of their action.

The weekly rating of depressive symptoms gave a significant difference between the drug and the placebo but further examination showed that this was due to a slight deterioration in the weekly rating of depression on the placebo. The improvement on the drug did not reach significance when compared with the clinical state just before the trial started. Sargant and Dally (1962) suggested that anxious patients with marked symptoms of depression did well on anti-depressive mono-amine oxidase in- hibitors and were not helped by sedatives given alone.

Significant 'non-specific' improvements produced by the placebo were seen in the daily but not the weekly ratings. The baseline for the former was assessed at the first interview following the unfamiliar physiological tests, so the symptoms may on that occasion have been rated as more severe than usual. Weekly ratings were made on the second and third visits when the patients were accustomed to the routine, and knew that nothing unpleasant would occur. The tablets were given without any promises of positive effects and this may have reduced the tendency to report non-specific improvement. Contrary to the findings of Black (1959) changes with the placebo were not related to the order in which the tablets were given.

In summary, amylobarbitone sodium alters several physiological variables and lessens the severity of one type of symptom group as compared with placebo. The change in the physiological variables is in the direction of those mean values occurring in normal control subjects (Lader and Wing, 1964). The results may be interpreted as meaning that theo levels of some aspects of activity of the centra $\bar{\Phi}$ nervous system are diminished by barbiturat $\mathbb{Q}$ therapy. The D score equation, originally obtaine $\bar{\phi}-$ to discriminate between anxious patients and normaf Th patients, was also successful at discriminating be tween the patients when they were on amylobarbp tone sodium therapy and placebo therapy. As far a the physiological variables measured in the preserf $\vec{\varphi}$ experiments are concerned, it appears that the of patients with anxiety states are quantitatively different from normals and that that difference can be lessened by sedatives. The 'normalizing' effect was not great which is in accord with the small though significant clinical changes.

In the previous paper it was postulated that the rate of habituation was of importance in the pathogenesis of anxiety states. Those people who habituated slowly were more prone to develop persisting overactivity of the central nervous system perceived in 'consciousness' as the emotion of anxiety. This activity could be damped down by general central nervous system depressant drugs such as barbitur- $\overline{0}$ ates with amelioration of perceived anxiety. Lowering of skin conductance fluctuation level by a seda- $\delta$ tive was found in the present experiment. The rate of $₹$ habituation was relatively less affected by the bar- 을 biturate, and this, considered in conjunction with the $>$ fact tha: the clinical changes were limited, is consistent with the hypothesis. A corollary of the hypo- $\bar{N}$ thesis is that a drug which has a specific anti-anxiety $\Omega$ effect, that is, one which produces marked clinical $N$ changes in all the symptom groups, should markedly స్心 
accelerate the rate of habituation of patients. Socalled minor tranquillizers claimed by the manufacturers to have such a specific effect have been introduced in recent years. It is hoped to carry out a formal multi-dose bioassay of a new 'anti-anxiety' drug against a barbiturate using as parameters those physiological variables and clinical ratings found in the present study to be sensitive to sedative effects.

\section{SUMMARY}

Twenty patients with anxiety states were given one week's treatment with amylobarbitone sodium, $65 \mathrm{mg}$. t.d.s., and one week's treatment with placebo in a balanced cross-over double-blind trial. At the end of each week's treatment, the palmar skin resistance was recorded during a standard habituation procedure; after a rest period, 20 identical auditory stimuli were applied automatically at intervals varying from 45 to 80 seconds.

The background skin conductance level tended to rise throughout the recording session on the placebo occasion whereas it dropped on the amylobarbitone sodium occasion. Habituation of the psychogalvanic reflexes to the stimuli was more rapid with the barbiturate and the number of spontaneous skin conductance fluctuations was lowered by the barbiturate.

The patients made daily ratings of the severity of their symptoms and weekly ratings of changes in the same symptoms were made at interview after the physiological tests. The symptoms were classified into four categories: physical (i.e., autonomic or muscular), general feelings of anxiety, situational anxiety, and depressive symptoms. Only the physical symptoms showed significant improvement on the drug as compared with the placebo.

The results were consistent with a theory of the mechanism of anxiety based on the relationship between the rate of habituation and the level of activity of the central nervous system which had been outlined previously.
This work was supported by grant no. MY-3561 from the National Institute of Mental Health of the U.S. Public Health Service.

The authors wish to acknowledge their indebtedness to Dr. M. Shepherd and Professor H. O. Schild for their advice and encouragement; to Dr. A. Maxwell for statistical advice; and to Miss M. W. Hill and her staff who organized the dispensing of the drugs. Thanks are also due to Eli Lilly \& Co. Ltd., for supplying the tablets used in the trial.

\section{REFERENCES}

Black, A. A. (1959). An investigation of placebo reactors. Unpublished dissertation for the Academic Postgraduate Diploma in Psychological Medicine (London University).

Cochran, W. G., and Cox, G. M. (1957). Experimental Designs, 2nd ed. Wiley, New York.

Coppen, A. J., and Mezey, A. G. (1960). The influence of sodium amytal on the respiratory abnormalities of anxious psychiatric patients. J. psychosom. Res., 5, 52-55.

Editorial (1962). Drugs for anxiety. Brit. med. J., 1, 38-39.

Fisher, R. A. (1954). Statistical Methods for Research Workers, 12th ed. Oliver and Boyd, Edinburgh.

Hamilton, M. (1958). Treatment of anxiety states. III. Components of anxiety and their response to benactyzine. J. ment. Sci., 104, 1062-1068.

(1959). The assessment of anxiety states by rating. Brit. J. med. Psychol., 32, 50-55.

Hargreaves, G. R., Hamilton, M., and Roberts, J. M. (1958). Treatment of anxiety states. II. Clinical trial of benactyzine in anxiety states. J. ment. Sci., 104, 1056-1061.

Lader, M. H. (1964). Effect of cyclobarbitone on the habituation of the psychogalvanic reflex. Brain, 87, 321-340.

in patients with anxiety states and in normal subjects. $J$. Neurol. Neurosurg. Psychiat., 27, 210-218.

Lewis, A. (1958). Between guesswork and certainty in psychiatry. Lancet, 1, 171-174, 227-230.

Malmo, R. B. (1957). Anxiety and behavioral arousal. Psychol. Rev., 64, 276-287.

- (1959). Activation: a neuropsychological dimension. Ibid., 66, 367-386.

McNemar, Q. (1955). Psychological Statistics, 2nd ed. Wiley, New York.

Raymond, M. J., Lucas, C. J., Beesley, M. L., O'Connell, B. A., and Roberts, J. A. F. (1957). A trial of five tranquillising drugs in psychoneurosis. Brit. med. J., 2, 63-66.

Rosner, H., Levine, S., Hess, H., and Kaye, H. (1955). A comparative study of the effect on anxiety of chlorpromazine, reserpine, phenobarbital, and a placebo. J. nerv. ment. Dis., 122, 505-512.

Sargant, W., and Dally, P. (1962). Treatment of anxiety states by antidepressant drugs. Brit. med. J., 1, 6-9.

Siegel, S. (1956). Nonparametric Statistics for the Behavioral Sciences. McGraw-Hill, New York.

Snedecor, G. W. (1956). Statistical Methods, 5th ed. Iowa State College Press, Ames, Iowa. 